\title{
Ensinar e aprender História: o que dizem os jovens do campo
}

Teaching and learning History: what they say the youth from rural areas

Astrogildo Fernandes da Silva Júnior*

\section{Resumo}

$\mathrm{O}$ artigo tem como objetivo refletir sobre como se efetiva o ensino de história em uma escola localizada no meio rural do município de Uberlândia, MG, Brasil. Especificamente buscamos registrar e analisar como os professores ensinam e como os jovens do campo aprendem história. Esta investigação tem como referencial metodológico a abordagem qualitativa de pesquisa educacional. A pesquisa de campo recorre a instrumentos variados como anotações em diário de campo, por meio das visitas à escola e das observações das aulas de história, questionário respondido pelos jovens estudantes e entrevistas orais com os gestores e professores de história. Conclui-se que os jovens estudantes são atores sociais plurais. Revelaram a preocupação com o mundo onde vivem. Possuíam visões positivas sobre o ensino de história, que pode ser justificado pela prática da professora da turma. Palavras-chave: jovens do campo; ensino de História; ensinar e aprender.

\begin{abstract}
The paper aims to reflect on how effective the teaching of history in a school located in a rural area of the municipality of Uberlândia, MG, Brazil. Specifically we seek to record and analyze how teachers teach and how young people learn the history of the field. This research is a qualitative methodological framework approach to educational research. The field research uses various instruments such as notes in a field journal, through school visits and observations of the lessons of history, questionnaire answered by students and young oral interviews with managers and teachers of history. We conclude that young students are plural social actors. Showed concern for the world in which they live. Had positive views on the teaching of history, which can be justified by observing the classroom teacher.

Keywords: youth from rural areas; teaching of History; teaching and learning.
\end{abstract}

\footnotetext{
* Professor Adjunto do Curso de História, Faculdade de Ciências Integradas do Pontal da Universidade Federal de Uberlândia (Facip/UFU). Doutor em Educação, Programa de Pós-Graduação em Educação da UFU. silvajunior_af@yahoo.com.br ${ }^{1}$
} 
Com a aprovação da Constituição Federal de 1988 e com a Lei de Diretrizes e Bases da Educação Nacional - LDB 9394/96, outras possibilidades para a escola rural começaram a ser pensadas de acordo com uma perspectiva crítica. Iniciativas diferentes, situadas no campo da educação popular, da política, da educação de jovens e adultos, passaram a exigir maior participação do Estado no meio rural brasileiro. Propostas de adequação da escola à vida do campo não estavam contempladas anteriormente na sua especificidade.

Segundo Leite (1999), a LDB/1996 promoveu a desvinculação da escola rural dos meios e da performance escolar urbana, exigindo da escola rural um planejamento ligado à vida rural e, de certo modo, desurbanizado. No entanto, mesmo diante das mudanças previstas pela referida Lei, as problemáticas ligadas à escola rural permaneceram. O autor sinalizava alguns problemas recorrentes nos anos 1990. Quanto aos alunos da escola rural, destacou a distância entre os locais de moradia/trabalho/escola e o acesso precário a informações gerais. A respeito da participação da comunidade no processo escolar, registrou o distanciamento dos pais em relação à escola, embora as famílias tenham a escolaridade como valor sociomoral. Quanto à ação didático-pedagógica, o autor acentuou a inadequação do currículo, geralmente, estipulado por resoluções governamentais, com vistas à realidade urbana.

Com o propósito de mudar as políticas educacionais, na última década do século XX e início do século XXI, houve uma instigante presença dos sujeitos do campo na cena política e cultural do Brasil. Os movimentos sociais denunciavam o silenciamento e o esquecimento de suas realidades por parte dos diversos órgãos governamentais e lutavam por uma escola do campo que não fosse apenas um arremedo da escola urbana, mas que estivesse atenta às singularidades dos seus sujeitos.

Nessa perspectiva, o debate sobre a educação do campo, no âmbito do estado de direito, como demanda e estratégia de luta pela emancipação e cidadania dos sujeitos que vivem ou trabalham no campo, vem ganhando espaço. As estratégias visam colaborar para a formação das crianças, jovens e adultos em direção a um desenvolvimento sustentável regional e nacional. Assim, as propostas têm como princípio a valorização dos saberes que a população rural produz nas suas experiências cotidianas, e a agenda de trabalho, para discutir e subsidiar a construção de uma política de educação do campo passa a incorporar o respeito à diversidade cultural. 
A educação, como um direito social e uma política de educação do campo, requer o reconhecimento da necessidade de ruptura com a dicotomia rural/ urbano. Com essa compreensão, é primordial impor novas relações baseadas na horizontalidade e solidariedade entre campo e cidade. O campo é, acima de tudo, espaço de cultura singular, rico e diverso. Concordamos com o Grupo Permanente de Trabalho e Educação no Campo (2005), ${ }^{2}$ ao defender os seguintes princípios pedagógicos: o papel da escola 1) é formar sujeitos, e isso deve articular-se a um projeto de emancipação humana; 2) é valorizar os diferentes saberes oriundos da diversidade dos sujeitos no processo educativo; 3 ) é reconhecer os diferentes espaços e tempos de formação dos sujeitos da aprendizagem, pois a educação no campo ocorre tanto em espaços escolares quanto fora deles; 4) é vincular a escola à realidade dos sujeitos; 5) é ter a educação como estratégia para o desenvolvimento sustentável; 6) é desenvolver a autonomia e a colaboração entre os sujeitos do campo e o sistema nacional de ensino.

Com base nesses princípios, a discussão em torno de ensino e aprendizagem em escolas rurais ganhou relevância nos movimentos sociais. Nos limites deste texto, propomos refletir sobre como se efetiva o ensino de história em escola localizada no meio rural do município de Uberlândia, MG, Brasil. Especificamente buscamos registrar e analisar como os professores ensinam e como os jovens do campo aprendem história. Organizamos o texto dividindo-o em três partes. Na primeira, apresentamos a perspectiva metodológica e o cenário da pesquisa; na segunda, focamos no registro e reflexão sobre os jovens estudantes; na terceira, nossa proposta se deteve no processo de ensinar e aprender história; por fim, tecemos algumas considerações.

\section{A PERSPECTIVA METODOLÓGICA E O CENÁRIO DA PESQUISA}

Esta investigação tem como referencial metodológico a abordagem qualitativa de pesquisa educacional, por favorecer uma visão ampla do objeto estudado e o envolvimento do pesquisador com a realidade social, política, econômica e cultural. Assim, conforme Pais (2001, p.110), "em ambiências qualitativas os critérios de seleção são critérios de compreensão, pertinência e não os de representatividade estatística". A abordagem qualitativa não se resume aos aspectos superficiais e limitados, pois permite considerar e respeitar 
a subjetividade dos sujeitos da pesquisa. Optamos pela pesquisa educacional qualitativa do tipo etnográfico. Segundo André (1995, p.27),

A etnografia é um esquema de pesquisa desenvolvido pelos antropólogos para estudar a cultura e a sociedade. Etimologicamente etnografia significa "descrição cultural". Para os antropólogos, o termo tem dois sentidos: 1) um conjunto de técnicas que eles usam para coletar dados sobre os valores, os hábitos, as crenças, as práticas e os comportamentos de um grupo social; 2) um relato escrito resultante do emprego dessas técnicas.

A etnografia tem sua origem na Sociologia e na Antropologia e, por isso, utiliza-se de relatos descritos de pessoas, situações e acontecimentos. André (1995) afirma que por meio de técnicas etnográficas de observação participante e de entrevistas intensivas é possível documentar o não documentado, ou seja, desvelar os encontros e desencontros que permeiam o cotidiano escolar.

Na pesquisa de campo, utilizamos instrumentos variados que nos auxiliaram no registro das experiências ${ }^{3}$ dos sujeitos e na coleta de dados, como anotações em diário de campo, por meio das visitas à escola e das observações das aulas de história, questionário respondido pelos jovens estudantes e entrevistas orais com os gestores e professores de história. Como nos ensina Ginzburg (2007), se a realidade é opaca, existem zonas privilegiadas - sinais, indícios -, que possibilitam decifrá-la; é, pois, necessário examinar os pormenores mais negligenciáveis, basear-se em vestígios imperceptíveis para a maioria.

Conforme Vianna (2007), a observação é uma das mais importantes fontes de informações em pesquisas qualitativas em educação. Para o autor, sem acurada observação não há ciência. Dessa forma, procuramos registrar as anotações realizadas nas visitas às escolas e, em particular, nas aulas de história, de forma detalhada, com o intuito de reunir os dados brutos das observações. Concordamos com o autor ao afirmar que não basta ao observador simplesmente olhar, mas é fundamental saber ver, identificar e descrever os diversos tipos de interações e processos humanos. Para isso, no trabalho de campo, é importante a concentração, a paciência, o espírito alerta, a sensibilidade e a energia física para concretizar a tarefa.

Para ter acesso às vozes, às manifestações anônimas, ao cotidiano, a micro-história, aos espaços informais que compõem a experiência e a cultura 
popular, valemo-nos dos referenciais da História Oral. Segundo Portelli (1997), a história oral, além de expressar a historicidade da experiência pessoal e o papel do indivíduo na história da sociedade, propicia ampliar os conhecimentos e as informações sobre um passado recente, por meio da versão de pessoas que o viveram. Conforme Clandinin e Connelly (2011), pesquisas narrativas são histórias vividas e contadas, são uma forma de compreender a experiência. Pelas narrativas orais, cada pessoa recria suas diferentes versões sobre um mesmo período, valendo-se dos elementos de sua cultura, socialmente criados e compartilhados, conta não apenas o que fez, mas o que gostaria de ter feito, o que acreditava fazer e o que pensa que fez. Para Clandinin e Connelly (2011), as pessoas vivem histórias e, no contar dessas histórias, reafirmam-se, modificam-se e criam novas histórias.

Segundo Benjamin (1994), as narrativas permitem trazer a experiência de volta à história. Para o autor, o narrador é o homem que sabe dar conselhos. A narrativa tem sua dimensão utilitária, pode se constituir em um ensinamento moral ou em uma sugestão prática ou um provérbio, ou uma forma de vida. Não são verdades absolutas, não é uma rua de mão única. Reside aí a beleza do trabalho com narrativas. Ainda de acordo com Benjamin (1993), nas narrativas o leitor é livre para interpretar.

No início da pesquisa, em 2010, realizamos uma investigação crítico-reflexiva da dimensão institucional ou organizacional, que, segundo André (1995), envolve os aspectos referentes ao contexto da prática escolar: formas de organização do trabalho pedagógico, estruturas de poder e de decisão, níveis de participação dos seus agentes, disponibilidades de recursos humanos e materiais, enfim, toda a rede de relações que se forma e transforma no acontecer diário da vida escolar. Dessa forma, na primeira fase focalizamos nossos estudos nos documentos das políticas públicas relativos ao ensino fundamental, em particular, sobre o ensino de história e do Campo: Lei das Diretrizes e Bases - LDB 9.394/96; Parâmetros Curriculares Nacionais - PCNs de história; Diretrizes Operacionais para a Educação Básica em escolas do campo e a Referência para uma política nacional de Educação do Campo.

Concomitante à análise dos documentos, realizamos uma revisão bibliográfica sobre ensino e aprendizagem de história, educação do campo e juventude. A proposta foi desenvolver uma investigação de cunho qualitativo etnográfico, combinando o emprego de fontes orais, escritas, a observação 
participante e dados quantitativos. Efetuamos o estudo dentro de uma proposta teórico-metodológica que considera a integração e a complementaridade do corpo teórico com os procedimentos metodológicos. Inspirados em Bourdieu (1982), defendemos que as opções técnicas, mais empíricas, sejam inseparáveis das opções teóricas na construção do objeto de estudo.

Neste texto detemos nossa análise na observação das aulas de história da turma do $9^{\circ}$ ano do ensino fundamental da "Escola Municipal Leandro José de Oliveira", localizada no meio rural do município de Uberlândia, que atendia a uma diversidade de estudantes, dentre eles, grande quantidade de alunos acampados e assentados. Recorremos também a entrevista realizada com a professora de história e com o gestor da escola, e à análise de um questionário aplicado com os jovens colaboradores da pesquisa.

Nossa escolha pelo $9^{\circ}$ ano do ensino fundamental se deu por um conjunto de fatores. Os estudantes desse período fecham o ciclo curricular do ensino fundamental. Alguns alunos encerram os estudos para ingressarem no mercado de trabalho. Os alunos que estudam em escolas no meio rural do município de Uberlândia e que continuarão os estudos precisam ou mudar-se para as cidades ou deslocar-se diariamente para escolas localizadas no meio urbano. Alguns ingressam no ensino médio, para inserção no ensino superior, outros tentam conciliar a entrada no mercado de trabalho para prover o próprio sustento e a continuação dos estudos. É um período de efervescência na vida, pois várias questões estão em mudança: o corpo, os afetos, os namoros, as paixões, as relações com a política, com a família, com a religião etc.

Estudavam na escola, em 2010, 320 alunos, distribuídos em dois turnos. No vespertino, 240 alunos do $1^{\circ}$ ao $9^{\circ}$ ano. Não oferecia a educação infantil, pois, segundo o diretor, a escola não possuía salas de aulas suficientes. No noturno, estudavam 80 alunos na Educação de Jovens e Adultos (EJA). A escola atendia, em 2010, alunos do movimento de ocupação da Fazenda Tapuã (Acampamento José dos Anjos), liderado pelo MST. Os participantes desse movimento não são mais acampados, pois conquistaram a posse da terra. A região é caracterizada pela expansão de culturas irrigadas, onde o cerrado cede lugar a grandes plantações de soja, milho, feijão etc. Na região, há crescente desenvolvimento das práticas de avicultura e suinocultura, dominadas por grandes empresas. É um meio rural, marcado de um lado pela agricultura familiar e, de outro, pelo agronegócio. 
Fizeram parte de nossa investigação os 14 estudantes do $9^{\circ}$ ano do turno vespertino e a professora de história. Os alunos tinham 3 aulas de história, de 50 minutos, ao longo da semana. Segundo o gestor, os jovens estudantes valorizam a escola. Não raro precisam trabalhar para ajudar no sustento da família, mas continuam estudando, são jovens pobres. Alguns jovens pensam em fazer um curso superior, mas a maioria se interessa mais por cursos profissionalizantes. São muito interessados em informática e gostam das aulas de educação física e dos filmes trabalhados pelos professores.

\section{JOVENS DO CAMPO: PERFIL SOCIOECONÔMICO E CULTURAL E ALGUMAS CONCEPÇÕES}

De acordo com Novaes (2006), os conceitos de juventude têm mudado no tempo e são sempre diferentes nas diversas culturas e espaços sociais. Dos 14 jovens desta investigação, 7 eram do sexo masculino e 7 do sexo feminino. Sete declaram-se brancos, 5 pardos e 2 pretos. Os dados indicam que o espaço escolar é multirracial e multicultural. ${ }^{4} \mathrm{~A}$ faixa etária dos participantes estava entre 13 e 17 anos. Quanto ao trabalho, ${ }^{5}$ nenhum dos entrevistados possuía vínculo formal. A renda familiar da maioria estava entre 1 e 2 salários mínimos.

A maior parte dos jovens colaboradores passou a infância na cidade. São filhos de acampados e assentados do MST; os pais passavam por dificuldades materiais na cidade e procuraram, no movimento, possibilidade de uma vida mais digna no meio rural. Para Wanderley (2010), nossa sociedade vivencia uma estreita simbiose entre morar e trabalhar no campo. É bem crescente a presença entre os residentes rurais de pessoas de origem urbana. A autora os denomina de "Retirantes às avessas". Ao serem questionados sobre quem era o chefe da família, 10 responderam ser a mãe, e 4 disseram ser o pai.

Ao longo das observações realizadas no espaço escolar, buscamos identificar influências culturais marcantes na construção identitária dos jovens. Percebemos que o modo de vida dos jovens estudantes e os marcadores culturais em escolas do meio rural se desenvolvem em meio às relações de circularidades com a vida urbana. Registramos fragmentos de nota de campo:

Um dos rapazes mandava recado, por meio de um adolescente menor, para uma das jovens que estava afastada. Uma delas trocou de roupa tirando o uniforme e 
também retocou a maquiagem. Outra tirou o prendedor de cabelos e prendeu a camiseta, deixando o umbigo visível. Um dos jovens não nos olhava, ou, quando olhava, era com desprezo. Usava boné, brincos, calça bem baixa. Outro cortou o cabelo e atrás fez o desenho de uma estrela. Esse jovem vivia no acampamento dos sem terra do município de Uberlândia. (Nota de Campo, 11 mar. 2010)

Os jovens estudantes das escolas são caracterizados por diferentes looks juvenis. Verificamos que a "moda urbana" faz parte do jeito de vestir-se e enfeitar-se dos jovens. De acordo com Carrano (2008, p.188),

O espaço urbano pode ser considerado como a referência material e simbólica de nossas sociedades. A dimensão hegemônica da urbanidade estende-se até mesmo aos territórios rurais, evidenciando aquilo que se considera a expressão da civilidade moderna - algo que não deixa mesmo de ser uma forma de etnocentrismo. As cidades, especialmente as megalópoles, entretanto, não devem ser pensadas apenas como espaços físicos, com características específicas no modo de ocupar o espaço, mas também como lugares onde ocorrem fenômenos expressivos que entram em tensão com as pretensões dominantes de racionalização da vida social.

Segundo Canclini (2003), o importante é não contrapor sociedades urbanas a sociedades rurais, mas procurar a compreensão das maneiras como se processa a coexistência de múltiplas culturas. $\mathrm{O}$ autor utiliza o conceito de hibridação cultural para referir-se a essas formas dispersas da cultura na modernidade. Conceitua hibridação como processos socioculturais nos quais estruturas ou práticas discretas, que existiam de forma separada, se combinam para gerar novas estruturas, objetos e práticas.

Questionamos se conheciam algum grupo jovem na sua localidade que participasse de atividades culturais como música, dança, rádio comunitária, patins, bicicleta, grafite e pichação. Os jovens foram unânimes em afirmar que não conheciam nenhum desses grupos. Segundo Brenner, Dayrell e Carrano (2005), os jovens brasileiros, em geral, participam pouco de projetos culturais, e o índice aumenta ainda mais entre os jovens do meio rural. Sposito (1996) afirma que quanto maior a ausência do Estado na oferta de equipamentos destinados à cultura e ao lazer juvenis, mais a rua adquire relevância em suas dimensões socializadoras. 
Na busca por compreender as identidades juvenis, consideramos relevante conhecer algumas concepções dos jovens: como se sentem em ser jovens, quais os problemas que mais os preocupam, os assuntos que mais lhes interessam e o que pensam sobre o futuro, dentre outras questões. A maior parte dos jovens afirmou que tem mais coisas boas que ruins em relação à condição juvenil.

Aproveitar a vida, liberdade e amizades foram os termos mais citados como justificativa da positividade em ser jovem. De acordo com Dayrell (2007), a sociabilidade é uma importante dimensão da condição juvenil. A turma de amigos é uma referência na trajetória da juventude. É com os amigos que eles fazem os programas, "trocam ideias", buscam formas de se afirmar diante do mundo adulto. Segundo Pais (2001), os amigos do grupo constituem o espelho de sua própria identidade, uma forma por meio da qual fixam similitudes e diferenças em relação aos outros.

Entre as piores coisas em ser jovem, destacaram a violência e a incompreensão dos adultos. No que se refere à violência, de acordo com Novais (2006), em várias pesquisas, quando se pergunta aos jovens, esse é um dos maiores problemas do Brasil. O termo incompreensão dos adultos também foi evidente nas respostas dos jovens estudantes. São sinais de uma singularidade desse espaço. Para Castro (2008), é comum os jovens que vivem no meio rural mencionarem que são tratados com descaso por parte dos adultos. Nesse caso, podemos levantar as seguintes hipóteses: a tradição familiar, as relações hierárquicas, verticais, a falta de diálogo e o distanciamento geracional. A autora afirma que ser jovem no campo é algo que está marcado por tensões entre o "sonho" e a luta pela terra, mas também pelas relações de hierarquia e os conflitos com a autoridade paterna.

Perguntamos aos jovens estudantes quais os problemas que mais os preocupam atualmente. Destacaram-se as seguintes respostas: violência, fome/ miséria e meio ambiente. As respostas revelam indícios de que os jovens percebem esses problemas como próximos do lugar, do território e das condições materiais em que vivem. Como registramos anteriormente, a renda familiar da maioria dos estudantes gira em torno de 1 a 2 salários mínimos, o que confirma que são “jovens pobres”, daí a preocupação iminente com problemas relacionados à fome e à miséria, e, por viverem em situação de risco, atentam para a segurança e a violência. Em relação a preocupação dos jovens com o meio ambiente, concordamos com Wanderley (2010), ao assegurar que se 
tornou universal a consciência da necessidade da preservação da natureza como condição de preservação do próprio planeta.

No processo de nossa investigação, observamos o quanto o lazer é importante para os jovens estudantes. Perguntamos o que gostavam de fazer no tempo livre. A maioria respondeu que preferem ir a festas com os amigos, jogar bola, ouvir música e namorar. Segundo Martins e Souza (2007), por um lado, a esfera das escolhas de lazer, muitas vezes, está condicionada a condições materiais para torná-las práticas concretas incorporadas à vida do jovem. Por outro lado, os gostos também são produzidos a partir do universo sociocultural, não estando essa dimensão restrita a características puramente individuais, livres de qualquer influência do meio ou das condições sociais e econômicas nas quais se insere o jovem.

Instigamos os jovens a se posicionarem sobre as seguintes frases: 1) Quando penso no futuro vejo mais riscos que possibilidades; 2) Quando penso no futuro tenho mais dúvidas do que certezas; 3) Experiências interessantes no presente são mais importantes que me preocupar com o futuro; 4) Para sair bem, é melhor se arriscar do que ser cuidadoso; 5) Não adianta fazer projetos porque o que acontece depende mais da sorte que de esforço.

As respostas revelaram que estão inseguros, desorientados em relação ao futuro, percebem mais riscos que possibilidades, têm mais dúvidas que certezas. Porém não descartam a importância de pensar no futuro e serem cuidadosos com o que fazem no presente para não comprometer seu futuro. São conscientes de suas responsabilidades para conquistarem um futuro melhor e não desconsideram o passado. A incerteza em relação ao futuro, característica que parece comum nessa geração, pode ser amenizada com a ação do Estado, reconhecendo os jovens como atores sociais em sua diversidade, portadores de direitos e deveres, favorecendo a realização das potencialidades dessa geração. Aos professores cabe exercitar o olhar dos jovens para o futuro, fortemente ancorado no passado e no presente. Assim, é possível fortalecer a consciência política e a responsabilidade social dos jovens estudantes.

Quando questionados a respeito dos valores mais importantes para uma sociedade ideal, os jovens escolheram em primeiro lugar a solidariedade. Em nossa investigação, o conjunto solidariedade; respeito às diferenças e respeito ao meio ambiente foi o mais citado. A ênfase na solidariedade como valor mais citado chama-nos a atenção para a existência de valores relacionados à noção de 
cidadania entre esses jovens. Ressaltamos, como uma revelação da pesquisa, a que retrata um universo de valores que contrasta tanto com o estereótipo do jovem como "individualista" e "descomprometido com os problemas sociais" como com a imagem, geralmente associada aos habitantes do campo, como "atrasados", "ignorantes" e "voltados para seus interesses próprios". Mais uma vez, evidenciamos a preocupação com o enfoque ambiental. $\mathrm{O}$ respeito ao meio ambiente sugere a formação da consciência ecológica expressiva entre os jovens.

Questionamos os jovens sobre o que pensam sobre a escola em que estudam. Por meio das respostas dos estudantes podemos assegurar que se configura uma ambiguidade caracterizada pela valorização do estudo como uma promessa futura, uma forma de garantir um mínimo de créditos para ter possibilidade de conseguir um lugar no mercado de trabalho, e a falta de sentido que encontram no presente. Comungamos com Silva e Guimarães (2010) quando afirmam que a escola continua a ser um espaço de enorme importância para amplos setores da população que não possuem biblioteca, laboratório e computadores em casa. Mantém-se como local para convívio multidisciplinar em torno dos saberes. Porém a escola investigada, de modo geral, apresentou-se aquém de suas potencialidades.

Além da escola, procuramos compreender as percepções dos jovens sobre a política. Concordamos com Krischke (2005), ao afirmar que a importância dos estudos sobre cultura política está nas evidências que eles podem proporcionar a respeito da disposição das pessoas em apoiar o regime democrático, apesar das eventuais desilusões acerca de um ou de outro partido ou governante.

A maior parte dos jovens registrou que a política influencia muito suas vidas, porém os jovens não influenciam a política. Mostrou-se insatisfeita e sem confiança nas instituições políticas. São indícios de que as políticas públicas não chegam aos jovens do campo. O desinteresse, a indiferença e o desconhecimento de questões ligadas à política são sinais de atitudes apolíticas, é o que Krischke (2005) denomina de apoliticismo. Em seguida nos deteremos nas especificidades do processo de ensinar e aprender história.

\section{O ENSINO DE HISTÓRIA NAS VOZES DOS JOVENS DO CAMPO}

Rüsen (2007, p.32) nos alerta para um dos problemas do ensino de história, ou seja, o saber histórico vir a ser percebido pelos estudantes como um 
"ramo morto da árvore do conhecimento". Pode aparecer como uma massa de informações a serem decoradas e repetidas para satisfazer os professores, com o intuito apenas de tirar boas notas. Dessa forma, não faz nenhuma ligação com a vida prática dos alunos e perde qualquer valor relativo no modo como as crianças e jovens pensam seu tempo, sua vida, seu mundo. Segundo o autor, até mesmo professores de história admitem que muitos conteúdos tratados nas aulas possuem esse caráter disfuncional e dificilmente desempenharão qualquer papel decisivo em situações concretas da vida.

Os Parâmetros Curriculares Nacionais (PCNs) de história (1998) sinalizam para outra perspectiva. De acordo com o documento, o ensino de história deve permitir que os alunos ampliem, gradativamente, o conhecimento acerca de sua realidade, relacionando-a e confrontando-a com outras realidades, em outros tempos e outros espaços. Assim, supõe-se que os professores possam fazer suas escolhas, estabelecer critérios, selecionar saberes e orientar suas ações. Nesse sentido, os alunos deverão ser capazes de:

- Identificar relações sociais no seu próprio grupo de convívio, na localidade, na região e no país, e outras manifestações estabelecidas em outros tempos e espaços.

- Situar acontecimentos históricos e localizá-los em uma multiplicidade de tempos.

- Reconhecer que o conhecimento histórico é parte de um conhecimento interdisciplinar.

- Compreender que as histórias individuais são partes integrantes de histórias coletivas.

- Conhecer e respeitar o modo de vida de diferentes grupos, em diversos tempos e espaços, em suas manifestações culturais, econômicas, políticas e sociais, reconhecendo semelhanças e diferenças entre eles, continuidades e descontinuidades, conflitos e contradições sociais.

- Questionar sua realidade, identificando problemas e possíveis soluções, conhecendo formas político-institucionais e organizações da sociedade civil que possibilitem modos de atuação.

- Dominar procedimentos de pesquisa escolar e de produção de texto, aprendendo a observar e colher informações de diferentes paisagens e registros escritos, iconográficos, sonoros e materiais. 
- Valorizar o patrimônio sociocultural e respeitar a diversidade social, considerando-os critérios éticos.

- Valorizar o direito de cidadania dos indivíduos, dos grupos e dos povos como condição de efetivo fortalecimento da democracia, mantendo-se o respeito às diferenças e a luta contra a desigualdade. (Brasil, PCN - Ensino Fundamental, 1998, p.43)

A análise dos Parâmetros Curriculares Nacionais evidencia uma preocupação do Estado com a inclusão da diversidade cultural no currículo de história, com a formação para a cidadania e com a intenção de integrar o ensino ao cotidiano do aluno. Conforme Pagès e Santisteban (2008), o ritmo acelerado das mudanças que se estão produzindo em todas as ordens da vida, a globalização, o novo imperialismo etc. são argumentos suficientes que justificam o ensino de história. Cada vez mais se torna importante relacionar a função educativa do ensino de história, seus propósitos e suas finalidades, com a cidadania democrática e com a formação cidadã dos jovens.

Um dos objetivos básicos do ensino de história é compreender o tempo vivido de outras épocas e converter o passado em "novos tempos". A história propõe-se a reconstruir os tempos distantes da experiência do presente e, assim, transformá-los em tempos familiares para nós. De acordo com Pais (1999, p.26),

O tempo é o espaço da história - espaço que se estende do passado ao presente e que nos convida a ir ao passado com questões do presente para voltar ao presente com o lastro do que se compreendeu do passado. Só voltando para trás o filme da história é que se torna compreensível o último fotograma: o presente.

Com o propósito de desvendar como os jovens estudantes se relacionavam com ensino e aprendizagem de história, eles foram questionados sobre o que mais valorizavam no estudo da história. O conhecimento do passado? A compreensão do presente? A orientação para o futuro? Ou as três situações? Do total de jovens investigados, a maior parte respondeu que é, ao mesmo tempo, conhecimento do passado, do presente e orientação para o futuro. Podemos relacionar esse resultado com a prática da professora Maria Helena, que procurava usar as diferentes linguagens no processo de ensinar e aprender, sempre articulando o presente, o passado e o futuro. 
Consideramos relevantes as palavras de Pais (1999), ao advogar que as origens das coisas presentes e futuras encontram-se no passado ou, em outros termos, a melhor maneira de compreender uma realidade é conhecer-lhe as pegadas, pois a incompreensão do presente e do futuro nasce da ignorância do passado. Na mesma perspectiva, Rüsen (2001) afirma que a compreensão do presente e a projeção do futuro somente são possíveis com a recuperação do passado. Daí a importância de o professor investigar como os alunos pensam o passado, pois acreditamos que esse tempo está presente no aluno de forma prática ou encapsulado.

Nas aulas de história, é importante que o professor desenvolva a noção de tempo rompendo com a ideia de continuidade e evolução, igual e único para toda a humanidade, e priorize o esforço de perceber a descontinuidade das mudanças. De acordo com as orientações dos PCNs, ao estudar as noções de tempo, é importante refletir sobre os diferentes níveis e ritmos de durações temporais. Durações relacionadas à percepção dos intervalos das mudanças ou das permanências nas vivências humanas. Essa concepção de tempo é baseada nos estudos de Braudel (1992); o autor situa a história em três escalões: à superfície, uma história dos acontecimentos, que se inscreve no tempo curto; a meia encosta, uma história conjuntural, que segue um ritmo mais lento; em profundidade, uma história estrutural, de longa duração, que põe em causa séculos.

Para Pagès e Santisteban (2008), a compreensão da temporalidade é fundamental para uma educação democrática. Esses autores destacam elementos como entender o presente, tomar decisões e pensar o futuro. Consideramos sua contribuição no que diz respeito à aprendizagem do futuro, quando afirmam que as aproximações ao estudo do futuro podem situar-se em três âmbitos:

a) las creencias, que han dado lugar a la escatologia y a la apocalíptica, también al milenarismo y al mesianismo, así como a los mitos del fin del mundo; b) las ideologias, que han producido las utopias, las cuales han jugado un papel muy importante en la configuración del pensamiento social contemporáneo; c) la ciencia, que utiliza la prospectiva para analizar la posible evolución de los acontecimientos en futuro, de tal manera que esta actividad se ha convertido en uma parte esencial de la ciencia y de las ciencias sociales, por ejemplo en la economia o en 
la política. Este tercer ámbito del futuro es el que más nos interesa desde la enseñanza. (Pagès; Santisteban, 2008, p.6-7)

A noção de tempo defendida pelos autores faz-nos avançar em relação aos PCNs de história. Concordamos com eles ao afirmarem que, no ensino de história, devemos conectar o estudo do passado com a prospectiva no futuro. O ensino de história deve apoiar-se nos pré-requisitos temporais necessários para introduzir o aluno na experiência histórica e deve ser ensinado desde os primeiros anos de escolaridade.

Ancorados em vertentes historiográficas que entendem a história como estudo da experiência humana no tempo, vemos que a história estuda a vida de todos os homens e mulheres, com a preocupação de recuperar o sentido de experiências individuais e coletivas. O documento sugere que esse deve ser um dos principais critérios para a seleção de conteúdos e sua organização em temas a serem ensinados com o objetivo de contribuir para a formação de consciências individuais e coletivas numa perspectiva crítica.

Os PCNs de história defendem a necessidade de reformular os conteúdos, priorizando a construção de problematizações históricas. Recomenda a apreensão de várias histórias lidas a partir de distintos sujeitos históricos, das histórias silenciadas. Reforça a importância de recuperar a vivência pessoal e coletiva dos estudantes. Na escolha dos conteúdos, a proposta é propiciar aos alunos o dimensionamento de si mesmos e de outros indivíduos e grupos em temporalidades históricas. Os conteúdos devem sensibilizar e fundamentar a compreensão de que os problemas atuais e cotidianos não podem ser explicados unicamente a partir dos acontecimentos restritos ao presente. Requerem questionamentos ao passado, análises e identificação de relações entre vivências sociais no tempo. Pagès (2011) avança nessa perspectiva, ao afirmar que aprender história pode ser uma ferramenta útil para o controle do tempo, em particular para o controle do futuro.

Para Anguera e Santisteban (2012), o estudo do futuro tem como objetivos descobrir ou inventar, examinar, avaliar e propor futuros possíveis, prováveis ou preferidos. Portanto, a razão principal de sua inclusão no ensino de história é contribuir para o trabalho pelo bem-estar do entorno e da humanidade. Os autores reforçam que uma das finalidades fundamentais do ensino de história é estabelecer relações oportunas entre passado, presente e futuro. 
O estudo do futuro dá sentido ao passado e ao presente. $\mathrm{O}$ ensino de história pode dotar o estudante de conhecimento e instrumentos necessários para construir o futuro, para pensar que o futuro não está escrito e não é produto de sorte ou azar, e sim que é responsabilidade nossa escrevê-lo com base na participação democrática. Assim, é possível diminuir as dúvidas e incertezas ante ao futuro, marcantes nas percepções dos jovens.

Ao inquirirmos os jovens estudantes sobre o significado da disciplina, identificamos que os colaboradores possuíam representações positivas da história. Prevaleceram as seguintes respostas: "história mostra o que está por detrás dos modos de vida do presente e explica os problemas atuais" e "história é uma fonte de aventura que estimula a imaginação". Acreditamos que a história, ao ser ensinada e apreendida, pode também ser fonte de prazer. Isso não quer dizer que o ensino de história deva ser apenas, ou, principalmente, uma arte de sedução. Mas, provavelmente, deve começar desse modo, quando o objetivo é seduzir os jovens estudantes para o campo da história. Concordamos com Pais (1999), ao afirmar que a cientificidade da história não impossibilita que esta se arme com estratégias de sedução.

Questionamos os jovens estudantes: "Que tipo de fontes históricas mais os agradam?”. A maior parte registrou que preferia os filmes de ficção, as narrativas de adultos e museus. Chamou-nos atenção a grande importância dada às narrativas dos adultos; como a escola reunia um grande número de jovens participantes do MST, eles tinham, na sua prática, o fato de ouvir os adultos, líderes do movimento. Quando lhes perguntamos em quais fontes mais confiavam, prevaleceram os livros escolares, as narrativas dos professores e os museus.

A ênfase dada aos museus como principal instrumento de aprendizagem e que inspira confiança pode ser compreendida pelo desejo de conhecer um museu, pois os colaboradores constroem uma representação positiva desse espaço como lugar da história. Percebemos que os filmes de ficção constituem um dos instrumentos favoritos de aprendizagem da história. No entanto, esse agrado não se traduz em confiança. Pais (1999) afirma que a organização futura do ensino de história, bem como de outras disciplinas, deveria contemplar o valor pedagógico do instrumento televisivo ou audiovisual. Os livros escolares e as narrativas dos professores não representam as fontes que mais agradam aos alunos, embora inspirem confiança. 
Defendemos que os livros didáticos, em sala de aula, precisam ser ampliados, complementados, criticados e revistos. O professor deve ter uma relação crítica, nunca de submissão ao livro de história, que, como todo texto, toda fonte, merece ser questionado, problematizado e amplamente explorado com os alunos. Ao ensinar história, o professor precisa considerar os saberes dos jovens do campo, é importante evidenciar a relação com a vida prática dos estudantes. Um ensino do campo e no campo, e não para o campo. Assim, é possível o ensino se efetivar em aprendizado. Aprender história pode contribuir para a formação de uma cidadania livre e solidária.

\section{CONSIDERAÇÕES FINAIS}

O mundo rural como categoria histórica se transformou, ao longo do tempo, como um espaço diverso, plural nos aspectos sociais, econômicos, históricos e culturais. O mundo rural é maior que o agrícola. Os grupos sociais que vivem nesse espaço interagem, cotidianamente, com os grupos sociais urbanos. Os jovens do campo, sujeitos desta pesquisa, mantêm uma relação de profunda interdependência com o espaço urbano. Vivem nas fendas entre os dois mundos. O espaço escolar é multicultural, multifacetado, apresenta singularidades, mas é profundamente marcado pela educação escolar e pela cultura urbana. Os jovens estudantes são atores sociais plurais. Muitos expressaram não se sentirem contemplados pelas políticas públicas, mas revelaram a preocupação com o mundo onde vivem. Demonstraram acreditar que podiam mudar o mundo, defenderam a solidariedade para com o próximo e a importância de valorizar o meio ambiente.

Apresentavam uma visão positiva sobre o ensino de história. A professora buscava incorporar diferentes fontes e linguagens no processo de ensinar e aprender história, e essa atitude pode justificar o interesse dos jovens estudantes em aprender história. Sentimos que o desafio para a professora é o de efetivar um ensino de história que contribua para o alargamento e aprofundamento do campo de reflexão dos jovens estudantes em relação à política e à cidadania.

Os jovens do campo só podem atribuir sentido ao que lhes é ensinado em história quando compreendem a lógica, os métodos e as perspectivas que orientam a produção do conhecimento específico da disciplina. Dessa forma, 
tão importante quanto estudar o conteúdo é estudar como o historiador realiza seu trabalho. Esse modo de aprender história exige consideração do que é conceitual contido na narração, na explicação, e também de como se constitui a base de procedimentos que gera determinada narrativa.

Defendemos a proposição de que o ensino de história na escola tem um papel político e cultural. O diálogo entre professores e estudantes, o conhecimento (conteúdos, metodologias fundamentadas teoricamente tanto na historiografia quanto na didática da história) e o mundo plural e diverso em que vivemos, são fundamentais. Por meio de um intenso e fértil compromisso de professores e estudantes, podemos não apenas evitar uma prática de ensino de história dogmática e ideológica, mas fomentar uma prática criativa e formativa dos jovens estudantes.

\section{REFERENNCIAS}

ANDRÉ, Marli. Etnografia da prática escolar. Campinas, SP: Papirus, 1995.

ANGUERA, Carles; SANTISTEBAN, Antoni. El concepto de futuro en la enseñanza de las ciência sociales y su influencia na participação democrática. In: FERNÁNDEZ, Nicolas de Alba; PÉREZ, Francisco F. García; SANTISTEBAN, Antoni. (Ed.) Educar para la participacion ciudadana en la enseñanza de las ciências sociales. Sevilla: Díada, 2012.

BENJAMIN, Walter. Experiência e pobreza. In: Magia e técnica, arte política. 5.ed. São Paulo: Brasiliense, 1993.

BENJAMIN, Walter. O narrador. In: Magia e técnica, arte política. 7.ed. São Paulo: Brasiliense, 1994.

BOURDIEU, Pierre. A economia das trocas simbólicas. São Paulo: Perspectiva, 1982.

BRASIL. Lei de Diretrizes e Bases da Educação Nacional Nova LDB (Lei no 9394/96). Rio de Janeiro: Qualithmark, 1997.

Constituição Federal de 1988. Disponível em: www.planalto.gov.br; Acesso em: 20 dez. 2005.

. Ministério da Educação - Diretrizes operacionais para a educação básica nas escolas do campo. Brasília, 2002.

. Ministério da Educação. Grupo Permanente de Trabalho de Educação do Campo. Referência para uma política nacional de Educação do Campo. Caderno de subsídios. Brasília, 2005. 
BRASIL. Proposta curricular de História. Ensino Fundamental. Brasília: MEC/SEF, 1998.

BRAUDEL, Fernand. Escritos sobre a História. 2.ed. São Paulo: Perspectiva, 1992.

BRENNER, Ana Karina; DAYRELL, Juarez; CARRANO, Paulo. Culturas do lazer e do tempo livre dos jovens brasileiros. In: ABRAMO, Helena Wendel; BRANCO, Pedro Paulo Martoni (Org.) Retratos da juventude brasileira. São Paulo: Ed. Fundação Perseu Abramo, 2005.

CANCLINI, Néstor Garcia. Culturas híbridas: estratégias para entrar e sair da modernidade. São Paulo: Edusp, 2003.

CARRANO, Paulo. Identidades culturais juvenis e escolas: arenas de conflitos e possibilidades. In: MOREIRA, Antonio Flávio; CANDAU, Vera Maria (Org.) Multiculturalismo: diferenças culturais e práticas pedagógicas. Petrópolis, RJ: Vozes, 2008.

CASTRO, Elisa Guaraná. As jovens rurais e a reprodução social das hierarquias: relações de gênero em assentamentos rurais - Gênero, juventude e o cotidiano dos assentamentos rurais. In: Reforma agrária e desenvolvimento: desafios e rumos da política de assentamentos rurais. Brasília: MDA; São Paulo: Uniara, 2008.

CLANDININ, D. Jean; CONNELLY, F. Micael. Pesquisa narrativa: experiências e histórias na pesquisa qualitativa. Uberlândia: Edufu, 2011.

DAYRELL, Juarez. A escola "faz" as juventudes? Reflexões em torno da socialização juvenil. Educ. Soc., Campinas, SP, v.28, n.100 - Especial, p.1105-1128, out. 2007. Disponível em: www.cedes.unicamp.br; Acesso em: 10 set. 2010.

GINZBURG, Carlo. Sinais: raízes de um paradigma indiciário. In: Mitos, emblemas, sinais. São Paulo: Companhia das Letras, 2007.

HALL, Stuart. Da diáspora: identidades e mediações culturais. Belo Horizonte: Ed. UFMG, 2006.

KRISCHKE, Paulo J. Questões sobre juventude, cultura política e participação democrática. In: ABRAMO, Helena Wendel; BRANCO, Pedro Paulo Martoni (Org.) Retratos da juventude brasileira. São Paulo: Ed. Fundação Perseu Abramo, 2005.

LARROSA, Jorge. La experiência de la lectura: estudios sobre literatura y formación. Barcelona: Laertes, 1996.

LEITE, Sérgio Celani. Escola rural: urbanização e políticas educacionais. São Paulo: Cortez, 1999.

NOVAES. Regina. Os jovens de hoje: contextos, diferenças e trajetórias. In: ALMEIDA, Maria Isabel Mendes de; EUGENIO, Fernanda (Org.) Culturas jovens: novos mapas do afeto. Rio de Janeiro: Jorge Zahar, 2006.

PAGĖS, Joan; SANTISTEBAN, Antoni Fernández. Cambios y continuaidades: apren- 
der la temporalidad histórica. In: JARA, M. A. (Coord.) Enseñanza de la Historia: debates y propuestas. Comahue: Educo (Editorial de la Universidad Nacional del Comahue, Argentina), 2008. p.91-127.

PAIS, José Machado. Consciência histórica e identidades: os jovens portugueses num contexto europeu. Oeiras: Celta Ed., 1999.

. Ganchos, tachos e biscates: jovens, trabalho e futuro. Porto: Ambar, 2001.

PORTELLI, Alessandro. História oral como gênero. Projeto História: revista do Programa de Estudos de Pós-Graduação em História da PUC-SP, São Paulo: Educ, 1997.

PORTINARI, Denise; COUTINHO, Fernanda Ribeiro. A roupa faz o homem: a moda como questão. In: ALMEIDA, Maria Isabel Mendes de; EUGENIO, Fernanda (Org.) Culturas jovens: novos mapas do afeto. Rio de Janeiro: Jorge Zahar, 2006.

RÜSEN, Jörn. História viva: teoria da história: formas e funções do conhecimento histórico. Brasília: Ed. UnB, 2007.

. Razão histórica - teoria da história: fundamentos da ciência história. Brasília: Ed. UnB, 2001.

SILVA, Marcos; GUIMARÃES, Selva. Ensino de História Hoje: errâncias, conquistas e perdas. Revista Brasileira de História, v.30, n.60, dez. 2010.

SPOSITO, Marília Pontes. Juventude: crise, identidade e escola. In: DAYRELL, Juarez (Org.) Múltiplos olhares sobre educação e cultura. Belo Horizonte: Ed. UFMG, 1996.

VIANNA, Heraldo Marelim. Pesquisa em educação: a observação. Brasília: Líber, 2007.

WANDERLEY, Maria de Nazareth Baudel. A sociologia rural na América Latina: produção de conhecimento e compromisso com a sociedade. Revista Alasru, Nueva Época, n.5, Análisis Latinoamericano Del Medio Rural, p.17-44, 2010.

\section{NOTAS}

${ }^{1}$ Apoio: Fapemig/Apes/CNPq, Editais: MCTI/CNPq/MEC/Capes n. 18/2012 e 13/2012. Pesquisa na Educação Básica Acordo Capes e Fapemig e Fapemig, Universal, 2013.

${ }^{2}$ O Grupo Permanente de Trabalho e Educação no Campo - GPTE (2005), a partir do diagnóstico "Perfil da Educação no Campo", elaborado pelo Instituto Nacional de Estudos e Pesquisas Educacionais Anísio Teixeira (Inep), referente ao sistema de ensino formal no meio rural, procurou levantar instrumentos para a construção de uma política pública de educação que atenda às demandas dos sujeitos do campo, concebendo-a como instrumento imprescindível para o desenvolvimento sustentável das populações do campo. 
${ }^{3}$ Para Benjamin (1993), a experiência é sinônimo de sabedoria e autoridade. Segundo Clandinin e Connelly (2011), experiência são as histórias que as pessoas vivem. Para Larossa (1996), experiência é aquilo que nos toca, nos acontece e, dessa forma, nos transforma.

${ }^{4}$ De acordo com Hall (2006), em sua obra Da diáspora: identidades e mediações culturais, as sociedades multiculturais não constituem algo novo. Segundo o autor, antes da expansão europeia (a partir do século XV) - e com crescente intensidade desde então - a migração e os deslocamentos dos povos têm constituído mais a regra que a exceção, produzindo sociedades étnica ou culturalmente mistas.

${ }^{5} \mathrm{O}$ "trabalho" é aqui entendido como fonte de renda, trabalho assalariado, não como trabalho laboral que é recorrente principalmente entre os jovens rurais, pois é comum ajudar os pais nos afazeres domésticos e agrícolas.

Artigo recebido em 21 de novembro de 2014. Aprovado em 23 de fevereiro de 2015. 